\title{
EFFICIENT AND COST EFFECTIVE MODEL FOR AN ECO-FRIENDLY SOLAR COLONY
}

\author{
Abhijit Kundu ${ }^{1}$, Soumyajit $\mathrm{Nath}^{2}$, Saheli $\mathrm{Nag}^{3}$, Saikat Bhattacharyya ${ }^{4}$, \\ Bap Sadhukhan $^{5}$, M. Ray Kanjilal ${ }^{6}$ \\ ${ }^{1}$ Department of ECE, Abacus Institute of Engineering and Management. \\ abhijitudayeyahoo.co.in \\ 2,3,4,5 Department of ECE., Narula Institute of Technology \\ \{soumyajit08nath, sahelinag, saikat.bhatt143, \\ bapis. khan\} @gmail.com \\ ${ }^{6}$ Department of ECE (MIETE, MISTE and MIEEE), Narula Institute of \\ Technology \\ mr.kanjilal@gmail.com
}

\begin{abstract}
A simple and successful design is developed which has the objective to put together a cost effective model, scaled down both in size and energy required for an average residential home driven through Solar Panels. It also deals with the autonomous illumination of streets of a model colony through solar panels to meet the requirements and attain the maximum efficiency of the available energy. The Photovoltaic system along with an inverter and intensity control circuit counts for the basic design. The effort deals with the efficient, cost effective and needful implementation of Photovoltaic systems which would be useful primarily in rural and remote parts of India for both social and economic development of the people.
\end{abstract}

\section{KEYWORDS}

Solar cell, intensity control circuit, compact fluorescent lamps, inverter transformer, LDR, ecofriendly, economic.

\section{INTRODUCTION}

Development of electricity infrastructure is one of the main hurdles in the development of rural society. India's grid system is considerably under-developed, with major sections of its populace still surviving off-grid. As of 2004 there are about 80,000 un-electrified villages in the country. Of these villages 18,000 could not be electrified through extension of the conventional grid [1]. Keeping in mind the vast and diversified contour of a country, it is hard to install grids in the remote areas such as forests, deserts and hilly regions. Again manual control of the street lamps in such areas is an impossible task. Autonomously operated solar powered CFL lamps through intensity control circuits are the best possible way to provide electricity in these areas which will be able to bring out a social, economical and most importantly eco-friendly development in the society.

Rupak Bhattacharyya et al. (Eds) : ACER 2013, pp. 387-392, 2013. (C) CS \& IT-CSCP 2013

DOI : 10.5121/csit.2013.3236 


\section{ANALYSIS}

In India the theoretical solar power reception on its land area alone is about 5 Peta Watt-hours per year $(\mathrm{PWh} / \mathrm{yr})$ for 300 clear, sunny days in a year. The daily average solar energy incident over India varies from 4 to $7 \mathrm{kWh} / \mathrm{m}^{2}$ with about 1500-2000 sunshine hours per year (depending upon location), which is far more than current total energy consumption [1].

A model colony and a prototype house had been designed based on solar energy to implement the circuitry showing its real life application. Figure 1 shows the entire block diagram and it has been divided into two parts - the prototype house in which a Compact Fluorescent Lamp (CFL) has been illuminated by the photo generated energy and on the other hand a model colony which constitutes of such solar houses and street lamps powered by solar panels operated through autonomous intensity controlled switching circuit.

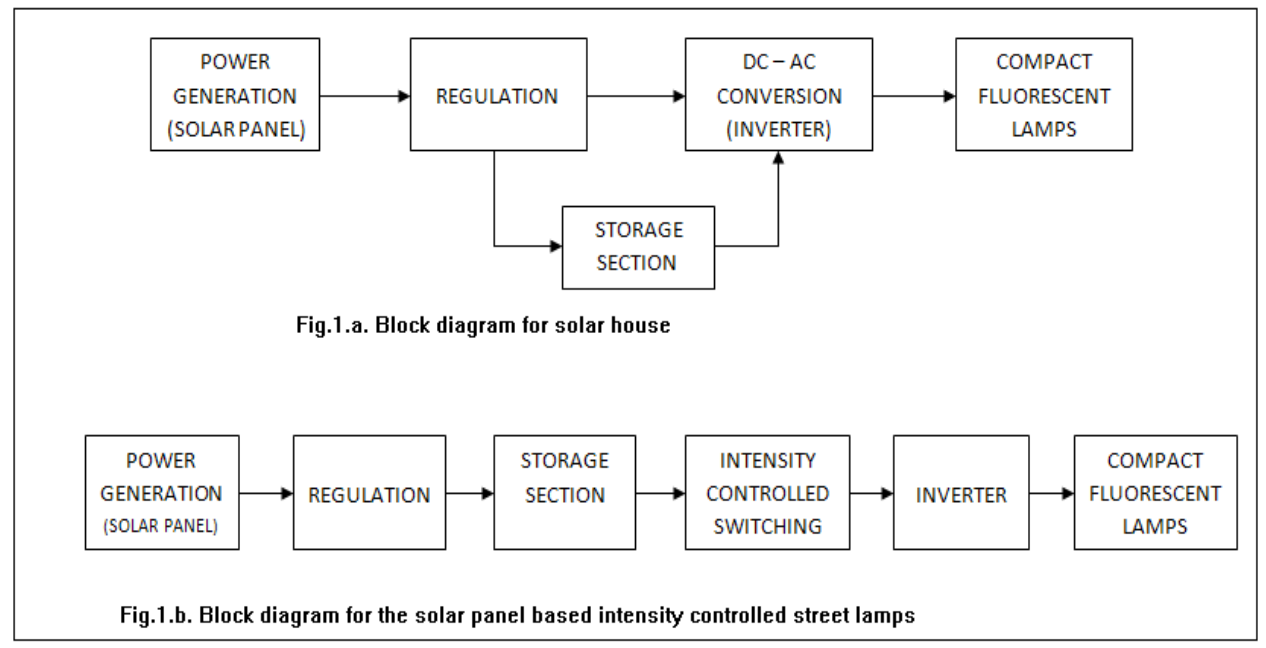

A solar panel of 10 watts $[2,3,5]$ is used as the primary source of power and also to simulate the entire experiment. The prototype house installs the solar panel which drives a regulation circuit shown in figure 2. Voltage regulators in various configurations are used in this block to regulate the photo generated power and remove backflow $[4,5]$. This regulated power is used to charge various kinds of storage elements such as Lead-acid, Nickel-Cadmium and Lithium-ion batteries to be used for different household purposes [4]. A Lead-acid battery (12 Volts and 7 Amperes) is used to deliver power to a Compact Fluorescent Lamp (CFL) rated at 9 watts in the house. 


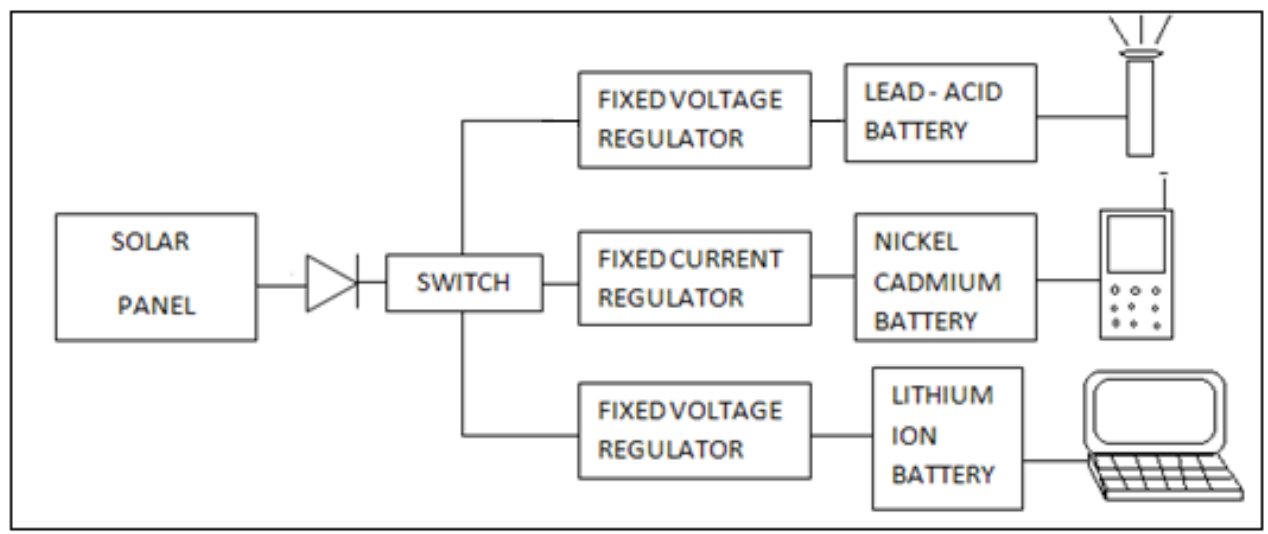

Fig.2 BLOCK DIAGRAM OF THE CIRCUIT

In addition to the rural areas, this project can also be implemented in the urban areas with an aim to reduce pollution. Since there is an abundance of AC operated equipment in urban areas, an inverter circuit is used to illuminate the CFL. The inverter circuit consists of miniature high frequency inverter transformer that has a $25 \mathrm{~mm} \times 20 \mathrm{~mm}$ x $5 \mathrm{~mm}$ ferrite core, 30 turns of primary, 15 turns of feedback, and 250 turns of secondary all concentric, wound on plastic frame then wrapped with a 'yellow' adhesive tape as shown in figure 3.This is a single transistor oscillator circuit. Current passed through primary winding inducts a magnetic field to the core and the core gives the energy back to the feedback winding with a delay determined by the core material and windings. The system then oscillates continuously on a frequency depending on this timing $[3,4$, $5,6]$.

As discussed earlier, autonomously operated solar powered CFLs along with intensity control circuits would be the best possible way to provide as well as conserve electricity in the remote and desolate areas. The street lamps consist of a circuit that incorporates a Light Dependent Resistor (LDR) and controls a relay through a transistor to switch on CFLs according to the intensity of the available sunlight. This circuit, as already stated, brings enormous help in areas where it is not possible to physically operate street lamps [5].

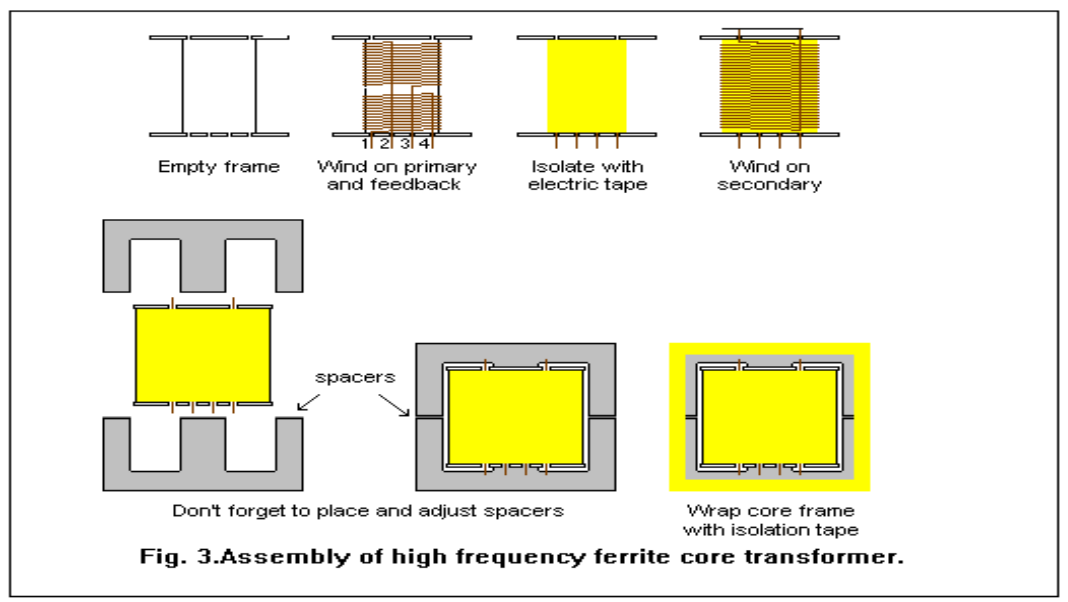


The circuit has a simple transistor switch shown in figure 4 with the base of the transistor connected to a voltage divider. The voltage divider has two resistors. The first is the $220 \mathrm{~K} \Omega$ potentiometer. The second resistor is the LDR. As light falls on the surface of the LDR, the LDR changes it's resistance. Higher the intensity of available light, leads to less the resistance of LDR and in turn of which the voltage drop across it becomes less. The less the light, the more the resistance and thus the voltage drop across it increases. As the voltage drop increases, so does the $\mathrm{V}_{\mathrm{B}}$ of the CL100 transistor and therefore the $\mathrm{I}_{\mathrm{CE}}$ increases accordingly, until the time that the current is enough to actuate the relay.
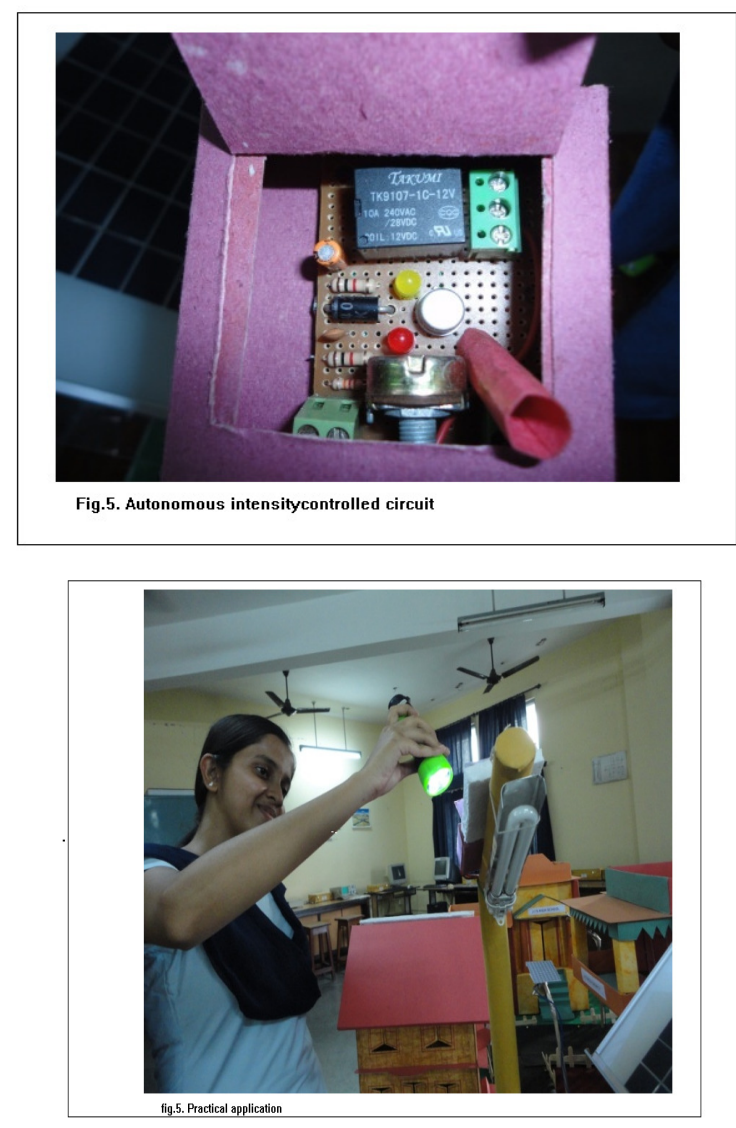

The amount of light needed to actuate the relay can be changed by changing the $220 \mathrm{~K}$ potentiometer. Basically, any change to the potentiometer will have an effect on the voltage drop of the LDR, i.e. its sensitivity is adjustable depending on the available light intensity. Practical applications are shown in figure 5

\section{RESULTS}

In the present work the practical circuits have been developed on Veroboard and also successfully simulated and the results are tabulated below. 
Table1. Regulator Blocks

\begin{tabular}{|l|l|l|l|}
\hline \multicolumn{1}{|c|}{ PORT NAMES } & \multicolumn{1}{|c|}{$\begin{array}{c}\text { DESIRED } \\
\text { OUTPUT }\end{array}$} & \multicolumn{1}{c|}{$\begin{array}{c}\text { PRACTICAL } \\
\text { OUTPUT }\end{array}$} & \multicolumn{1}{c|}{$\begin{array}{c}\text { BATTERY } \\
\text { CONNECTED }\end{array}$} \\
\hline PORT A & 12 Volts & 11.79 Volts & Lead-Acid \\
\hline PORT B & 5 Volts & 4.99 Volts & Lithium-ion \\
\hline PORT C & $12 \mathrm{~V}, 0.6 \mathrm{Amps}$ & $12 \mathrm{~V}, 0.6 \mathrm{Amps}$ & Nickel-Cadmium \\
\hline
\end{tabular}

Table2. Inverter block

\begin{tabular}{|l|l|l|}
\hline PARAMETERS USEI & DESIRED OUTPUT & PRACTICAL OUTPU' \\
\hline OUTPUT WAVEFORN & Sinusoidal & Modified Sine Wave \\
\hline VOLTAGE & $220 \mathrm{~V}$ & $\approx 150 \mathrm{~V}$ \\
\hline POWER & 40 Watts & More than 40 Watts \\
\hline FREQUENCY & High Frequency & High Frequency \\
\hline
\end{tabular}

Table3. AUTONOMOUS INTENSITY CONTROL SWITCH

\begin{tabular}{|l|l|l|l|l|}
\hline TIME & $\begin{array}{l}\text { RESISTANCE } \\
\text { OF LDR }\end{array}$ & $\begin{array}{l}\text { STATUS } \\
\text { OF RELAY }\end{array}$ & $\begin{array}{l}\text { STATUS O } \\
\text { YELLOW }\end{array}$ & $\begin{array}{l}\text { STATUS OF } \\
\text { RED LED }\end{array}$ \\
\hline DAY & $\begin{array}{l}\text { A few Ohms Depending } \\
\text { on intensity of light }\end{array}$ & Turned Off & Off & On \\
\hline NIGHT & In range of mega Ohms & Turned On & On & On \\
\hline
\end{tabular}

Figure 6 shows the modified waveforms of the inverter block.

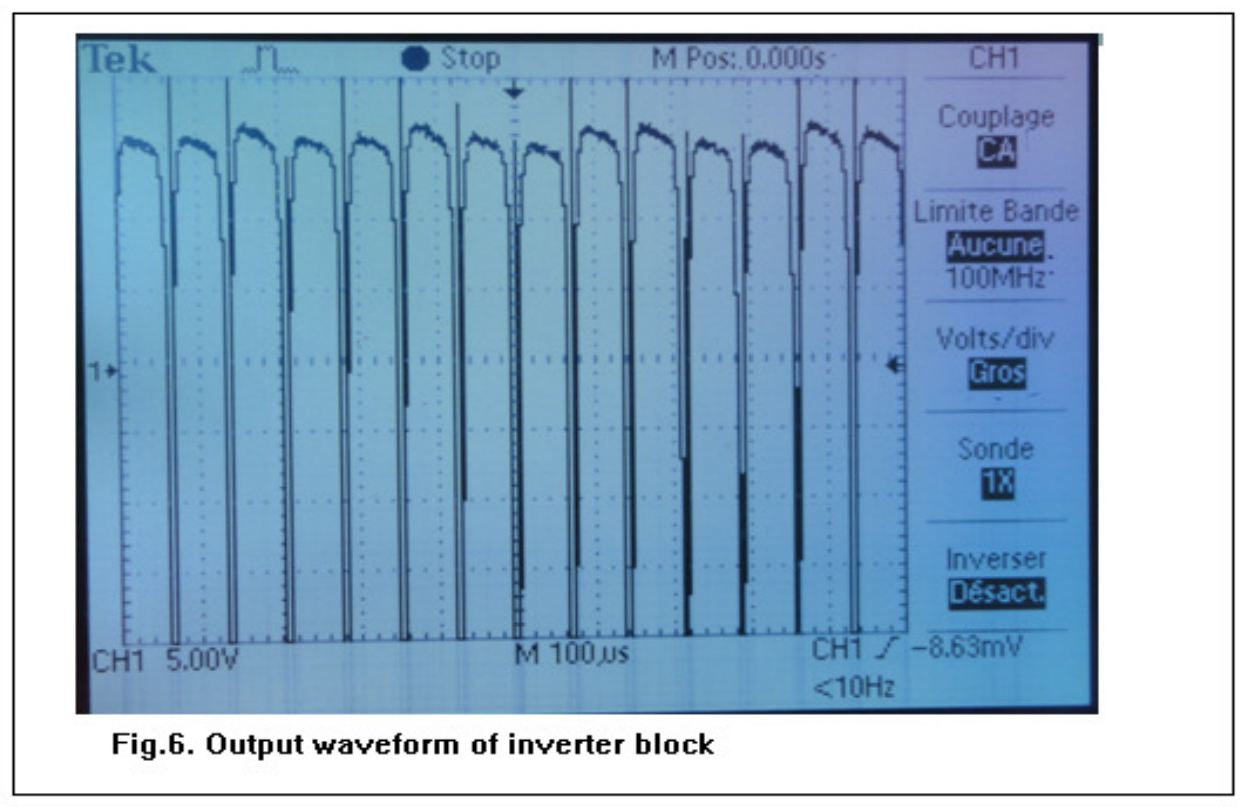




\section{CONCLuSion}

The concept of solar powered prototype house along with the intensity controlled switching circuit when implemented in the long run on practical fields to manage rural and urban development would definitely be a big leap towards reducing Global Warming and attaining a Green Country stature.

\section{REFERENCES}

[1] Muneer T, Asif M, Munawwar S: 'Sustainable production of solar electricity with particular reference to the Indian economy', RENEWABLE \& SUSTAINABLE ENERGY REVIEWS, pp: 444-473, OCT 2005.

[2] BEN G. STREETMAN: 'Solid State Electronics Devices', Prentice Hall of India Pvt. Ltd., 4th Edition, pp. 215-217, 677.

[3] J. MILLMAN, C. HALKIAS: 'Integrated Electronics: Analog and Digital Circuits and Systems', 1991, Tata McGraw Hill Publishing Company Ltd., pp. 81-83, 483-496, 698-699.

[4] ROBERT L. BOYLESTAD and LOUIS NASHELSKY: 'Electronic Devices and Circuit Theory', 9th Edition, Pearson Education Prentice Hall, pp. 232-235.

[5] J.B. GUPTA: 'Electronic Devices and Circuits', 3rd Edition, S.K. Kataria \& Sons. , pp. 354-357, 394398, 418-436, 472-480, 686-699.

[6] D. CHATTOPADHYAY, P.C. RAKSHIT, B. SAHA, N.N. PURKAIT: 'Foundations of Electronics', 2nd Edition, New Age International (P) Ltd. , pp. 274-277, 309-333.

\section{AUTHORS}

ABHIJIT KUNDU received the B.Tech \& M.tech degree in Electronics and Communication Engineering from the University of W.B.U.T, Kolkata, West Bengal, in 2007 \&2010 respectively. Currently, He is an Assistant Professor of Electronics and Communication Engineering of Abacus Institute of Engineering \& Management, West Bengal, India. His teaching and research areas include Microwave Engineering, Electro Magnetic Theory, Solid State Devices. He has few paper on PIN diode and MESFET. Abhijit Kundu (Assistant Professor) may be reached at abhijituday@yahoo.co.in

DR. MAITREYI RAY KANJILAL is at present Professor and Head in department of Electronics and Communication Engineering at Narula Institute of Technology, Kolkata, West Bengal, India. She has a wide teaching experience since 1998 in the colleges under C.U, Asansol engineering College, Narula Institute of Technology. She was also Head of the Department ECE and EIE departments at Techno India College of Technology, Kolkata, India. She has received the Ph.D from The University of Calcutta in the Year 2000. She is associated with different universities for various academic activities and also a life member of IETE, ISTE and Professional member of IEEE (USA), IEEE-ED society (USA), IEEE-MTTs (USA). Her field of interest in research is low and high frequency semiconductor devices and their applications, microelectronics and VLSI. Dr Ray Kanjilal is also the author of three books namely - Basic Electrical and Electronic Engineering- Vol - 1 (Kolkata, West Bengal, JB Book and Learning, 2010), Basic Electrical and Electronic Engineering- Vol - 2 (Kolkata, West Bengal, JB Book and Learning, 2011) and Analog Electronic Circuits (Kolkata, West Bengal, JB Book and Learning, 2012) and she has also reviewed books published by Pearson-Prentice Hall and Tata Mc Hill. Dr. Maitreyi Ray Kanjilal may be reached at mr.kanjilal@gmail.com.

SOUMYAJIT NATH, SAHELI NAG, SAIKAT BHATTACHARYYA, BAP SADHUKHAN are Student of ECE Dept., Narula Institute of Technology of 2012 batch. 